\title{
Premature Termination of Haemodialysis (PTHD) Sessions in a Tertiary Hospital in Nigeria: Prevalence and Causes
}

\author{
Umezurike Hughes Okafor*, Ruth Uzoh, and Samuel Obinna Edeh \\ Renal Unit, Department of Medicine, ESUT Teaching Hospital Parklane Enugu, Nigeria
}

*Corresponding author: Okafor UH, Renal Unit, Department of Medicine, ESUT Teaching Hospital Parklane Enugu, Nigeria, Tel: +2348033130014; E-mail: umehughes@yahoo.com

Received: 14 Sep, 2020 | Accepted: 08 Oct, 2020 | Published: 13 Oct, 2020

Citation: Okafor UH, Uzoh R, Edeh SO (2020) Premature Termination of Haemodialysis (PTHD) Sessions in a Tertiary Hospital in Nigeria: Prevalence and Causes. Int J Nephrol Kidney Fail 6(4): dx.doi.org/10.16966/2380-5498.201

Copyright: (c) 2020 Okafor UH, et al. This is an open-access article distributed under the terms of the Creative Commons Attribution License, which permits unrestricted use, distribution, and reproduction in any medium, provided the original author and source are credited.

\section{Abstract}

Background: Haemodialysis adequacy is depended on completion of the prescribed haemodialysis duration. Premature termination of haemodialysis occurs when there is a complication that cannot be managed. The aim of this study is to determine the prevalence and causes of premature termination of haemodialysis in a tertiary hospital in Nigeria.

Methodology: This is a retrospective study. All patients that had premature termination of haemodialysis at the renal unit of ESUT teaching hospital Parklane Enugu during the study period $-1^{\text {st }}$ January to $30^{\text {th }}$ June 2018 were recruited for the study. Their biodata and clinical details were documented. The parameters were entered in a spreadsheet and analysed using SPSS package. The results obtained were presented in text, tables and chart. $P$ value less than 0.05 was significant.

Results: A total of 405 haemodialysis sessions was done during the study period in 183 patients. Haemodialysis were terminated prematurely in 52 (12.8\%) dialysis sessions in 42 patients, 23 males and 19 females. The mean age was $49.9 \pm 13.4$ years. Most patients had CKD and used femoral catheters as vascular access. Nonclinical complications caused PTHD in $78.8 \%$. Intradialytic hypotension and severe body weakness were the commonest clinical complication while vascular access dysfunction, dialysate alarm and extracorporeal blood clot were the commonest non clinical complications. Two (3.8\%) patients terminated their HD against medical advice. The mean duration of HD was $165.7 \pm 43.7$ minutes, for those with clinical complications was $176.4 \pm 44.4$ minutes and those with nonclinical complications was $162.7 \pm 43.1$ minutes $(P=0.1985)$.

Conclusion: The prevalence of PTHD was $12.8 \%$ and the nonclinical complications especially poor vascular access were the commonest cause of PTHD. There is need for enhanced training of the HD staff especially the technicians and nurses.

Keywords: Premature; Termination; Haemodialysis; Complications

\section{Introduction}

Haemodialysis is the commonest renal replacement therapy globally and constitute up to $90 \%$ of renal replacement therapy available and/or accessible to patients in most developing countries $[1,2]$. It has been in use for more than 6 decades, and has undergone various stages of development during this period. This has been associated with marked improvement in acceptability, accessibility, tolerability and outcome of haemodialysis. However, in most economically disadvantaged countries, haemodialysis is either non available, rudimentary or not developing as witnessed in many developed countries. Though the first haemodialysis in Nigeria was done in 1980 [3], it is still not readily available and development is very slow. Acute and chronic kidney diseases is common in Nigeria with a prevalence of about $12 \%$ and $13 \%$ respectively, accounting for $5 \%$ of hospital admissions [4-6]. Nigeria with a population of about
200 million has less than 200 haemodialysis centers, lesser number of nephrologist, fewer haemodialysis nurses and scanty haemodialysis technicians. Most haemodialysis centers are in the urban areas and mainly managed by private establishments. There is no precise policy or subventions from government or non-governmental agencies to aid either patients or facilities for sustenance of haemodialysis in Nigeria.

ESRD is increasing both in incidence and prevalence globally, with the black population being at higher risk than white [7]. It poses a great challenge for health sector and consumes a large proportion of health care finances. The impact is even more significant for developing countries that face the double burden of infectious diseases and growing problem of non-communicable diseases [8,9]. There is paucity of renal replacement therapy in these developing countries, Africa contributes only $4.5 \%$ to the global dialysis population [10]. 
However, with the rising incidence of patients with kidney failure and increasing awareness of management of kidney failure including haemodialysis, it is anticipated that there will be upsurge in the provision of haemodialysis service in various countries of Africa.

Despite many technical advances, morbidities and mortality of patients on haemodialysis remain unacceptably high and their quality of life often not satisfactory [11]. Complications are one of the greatest challenges in haemodialysis and this may occur as a result of clinical or technical challenges. They can present as acute or chronic complications, the acute complications presenting as immediate (intradialysis) or delayed (postdialysis). Clinical complications including muscle cramp, pruritus, headache, abdominal pain, hypotension, hypertension, vomiting, restlessness, convulsions, unconsciousness, weakness etc has been reported [12]. Severities in terms of morbidity and outcome varies, it may be asymptomatic and/ or may be fatal. Occasionally haemodialysis session can be terminated prematurely due to irremediable clinical or technical complications.

The aim of this study was to determine the prevalence and causes of premature termination of haemodialysis sessions in a tertiary health facility in Nigeria.

\section{Methods}

This is a retrospective cross sectional study.

\section{Location}

The study location was the haemodialysis unit of Enugu State University Teaching Hospital Parkane which was established in February 2016, equipped with 5 Nikkiso haemodialysis machines. The personnel include nephrologists, resident doctors, nurses, a technician, porters and orderlies. The nurses and technician had onthe-job training for 2 months by a dialysis nurse and technician from another teaching hospital in Nigeria. The unit attends to patients from the parent teaching hospital, and also referrals from hospital within the state and other neighboring states of Abia, Ebonyi, Anambra, Imo, Cross River and Benue state.

\section{Population}

The study population was all patients who presented for haemodialysis at the center from $1^{\text {st }}$ January to $30^{\text {th }}$ June 2018 . The ethical clearance for the study was obtained from the ethical committee of the ESUT teaching hospital Parklane Enugu, approval no ESUTHP/EPR/073 on $3^{\text {rd }}$ November 2019. The permission to use the patient's data was obtained from the medical advisory committee of the hospital, however the identity of the patients were not included thus consent were waived. The study was done in accordance with the principles of Helsinki declarations. The information of the patients obtained will remain confidential.

\section{Haemodialysis procedure}

The patients were assessed clinically on presentation and the parked cell volume also assessed. The HD machine was prepared, lined and the prescribed dialysis programmed which usually included target spot $\mathrm{KT} / \mathrm{V}$ 1.4, dialysate flow rate $500 \mathrm{ml} /$ minute, blood flow rate 200-400 $\mathrm{mL} /$ minutes (patient dependent), heparin $1000 \mathrm{IU}$ bolus and $1000 \mathrm{IU} /$ hour, ultrafiltration volume and size of dialyser is patient dependent. Patients were connected through the vascular access to commence the $\mathrm{HD}$. The patient's clinical state including blood pressure and basic HD parameters including conductivity, blood, dialysate and heparin flow rate were checked and recorded every 30 minutes till the termination of the HD. The immediate post HD clinical states of the patients were also noted.

\section{Data collection}

The medical records of the patients selected for the study were retrieved. Their bio-data, clinical and haemodialysis parameters including the blood pressure, reason for terminating the haemodialysis were documented.

The causes of PTHD were classified as clinical and nonclinical depending on patient's presentation. Clinical complications were those that the patients had symptoms and/or signs associated with the complication. The non-clinical complications were those complications that were not associated with symptoms or signs in the patients.

\section{Data analysis}

The data obtained was entered in a spread sheet and analyzed using statistical package of social sciences (SPSS) vs. 22 (IBM NY USA). The result obtained was presented in text, tables and charts as means, standard deviations, frequencies and proportions. The student $\mathrm{T}$ test was used to assess difference and $\mathrm{P}$ value less than 0.05 was considered significant.

\section{Results}

One hundred and eighty-three patients had a total of 405 haemodialysis sessions during the period studied. Fifty-two (12.8\%) sessions in 42 patients were discontinued without completing the duration (premature termination). There were 23 (54.8\%) males, with male to female ratio of $1.2: 1$. The mean age was $49.9 \pm 13.4$ years. Thirty-three patients had chronic kidney disease and 9 patients had acute kidney injury. Thirty-Six (85.7\%) patients used femoral catheters, 3 (7.1\%) patients used tunneled jugular catheter, 1 (2.4\%) used arteriovenous fistula and $2(4.8 \%)$ patients initially used femoral and later tunneled internal jugular catheters. The femoral catheters were replaced monthly for each patient. The prescribed HD duration was 4 hours for all the patients.

Majority of the patients (78\%) had a single episode of PTHD. The detail of the frequency of PTHD per patient is as shown in figure 1.

\section{Causes of premature termination of HD sessions}

Majority of PTHD were caused by nonclinical complications (Figure 2a). The details of the complications were shown in figure $2 \mathrm{~b}$.

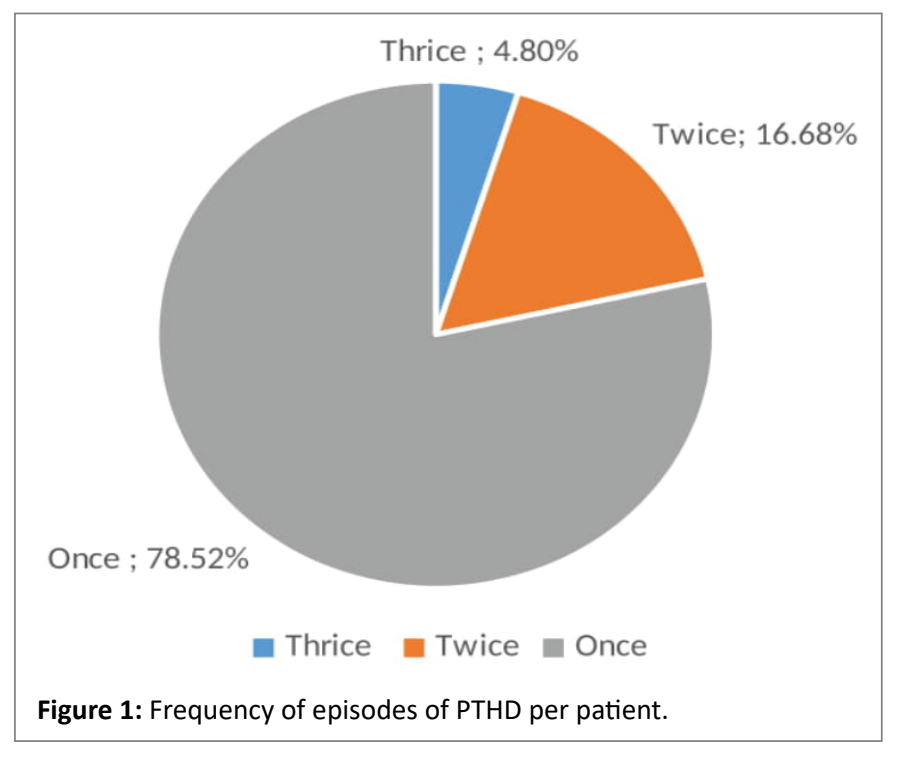




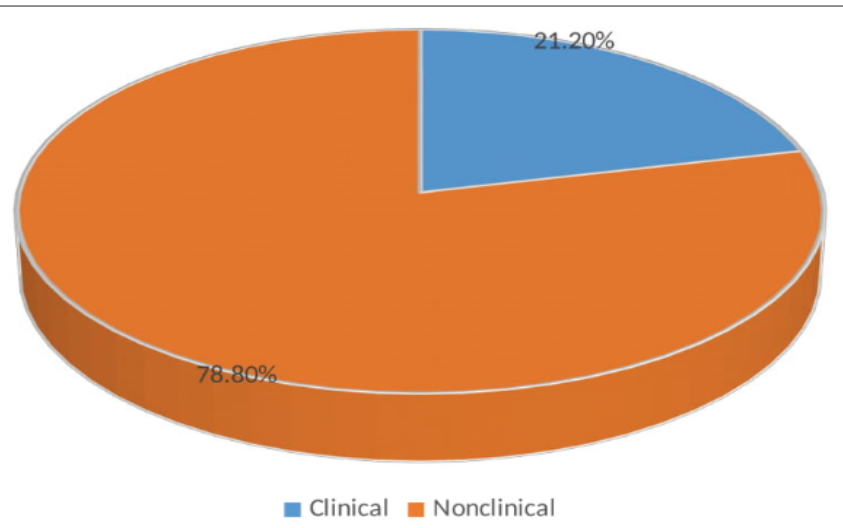

Figure 2a: Causes of PTHD.

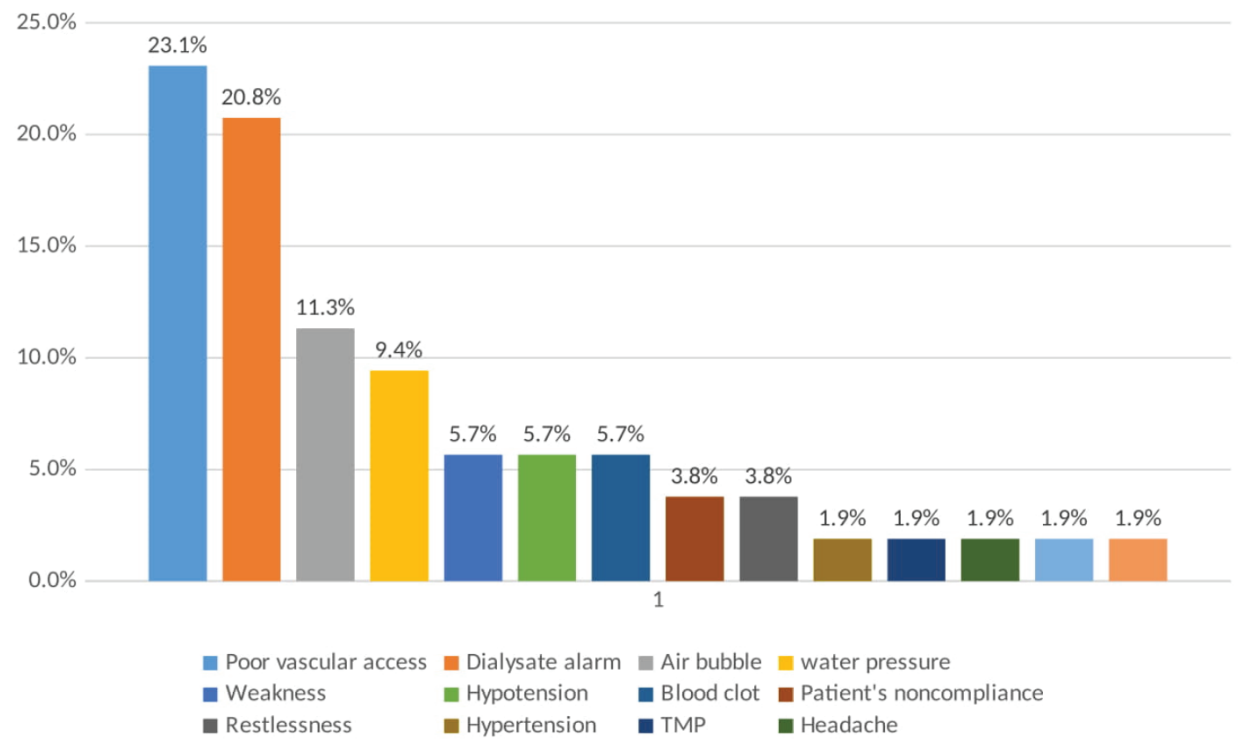

Figure 2b: Causes of PTHD.

\section{Clinical complications}

Clinical complications caused PTHD in $21.2 \%$ of patients. Intradialytic hypotension and severe weakness were the commonest clinical complications causing $27.3 \%$ of respectively. The details are shown in figure 3.

\section{Nonclinical complications}

A total of 41 (78.8\%) PTHD were caused by nonclinical complications. Poor vascular access, dialysate and air bubble alarm were the commonest and caused PTHD in $29.3 \%, 26.8 \%$ and $14.6 \%$ of PTHD sessions respectively. The details are shown in figure 4.

\section{Duration of HD}

The mean duration of HD before it was discontinued was $165.7 \pm$ 43.7 minutes with a range of 60 to 220 minutes. Duration for those with clinical complications was $176.4 \pm 44.4$ minutes and for those with nonclinical complications was $162.7 \pm 43.1$ minutes $(\mathrm{P}=0.1985)$. The distribution of the duration of HD is as documented in table 1.

\section{Discussion and Conclusion}

Dialysis adequacy is measured using urea reduction ratio (URR) and/or KT/V where $\mathrm{K}$ is the urea coefficient, $\mathrm{T}$ is duration of dialysis and $\mathrm{V}$ is volume of distribution. The National Kidney Foundation Dialysis Outcomes Quality Initiative (KDOQI) Clinical Practice Guidelines recommends URR and Kt/V of $70 \%$ and 1.4 respectively as a measure of adequate haemodialysis [13]. Appropriate haemodialysis treatment time is thus key to achieving adequate and fruitful haemodialysis. In this study the prevalence of PTHD was $12.8 \%$, this is lower than $15.4 \%$ reported by AL-Jabbar Kadhim MA, et al. [14] in Iraq but higher than $6.8 \%$ reported by Rocco MV, et al. [15] in United State of America. PTHD occurred once in $78 \%$, twice in $17 \%$ and thrice in $5 \%$ of patients, thus most of the patients had a single episode during the study. This is not consistent with reports of other studies where few patients constitute the greater proportion of those with PTHD because they had multiple premature terminations $[14,15]$. The mean duration of HD session in this study was less than three hours which is less than $75 \%$ of the 4 hours prescribed for conventional HD in the center. 


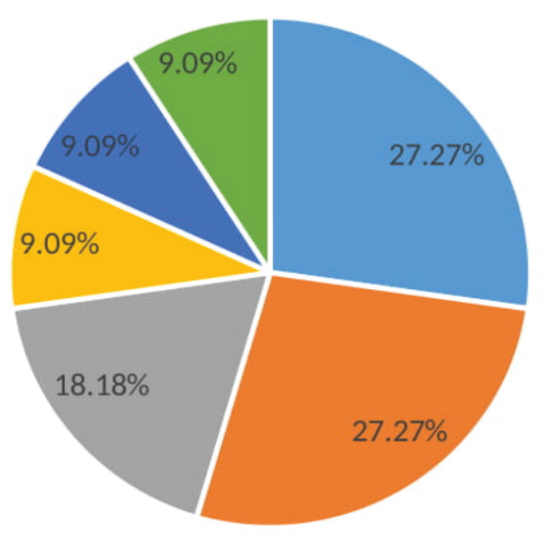

Weakness Hypotension Restlessness Headache Muscle cramp Hypertension

Figure 3: Clinical complications.

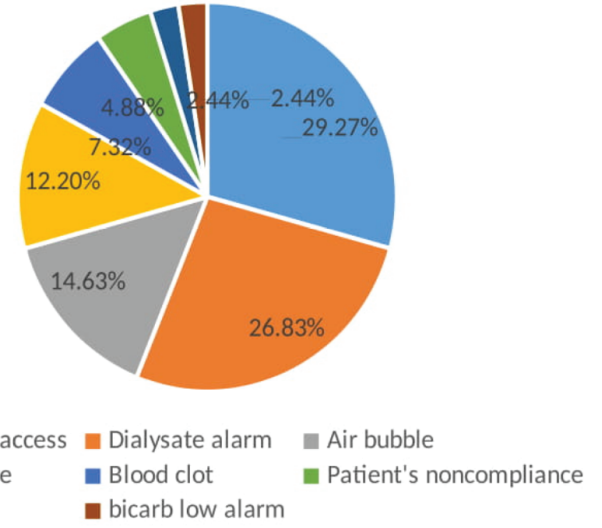

Figure 4: Nonclinical complications.

Held PJ, et al. [16] reported higher morbidity and mortality in patients on conventional haemodialysis with treatment time less than 3.5 hours as in this study. This was further highlighted by earlier report of better outcome among the European and Japanese than the American population which was attributed to longer duration of haemodialysis ( $\geq 4$ hours) among the Europeans and Japanese $[17,18]$.

Premature termination of haemodialysis usually occur when complications develops during the dialysis to avert an unpleasant outcome. These complications could be clinical in which the complications occur within the patient and associated with clinical manifestation or nonclinical in which the complication is extracorporeal and may not be associated with clinical manifestation. In this study $21.2 \%$ and $78.8 \%$ of PTHD were caused by clinical and nonclinical complications respectively. It was also noted that those that were terminated as a result of nonclinical complications had shorter duration of HD though not statistically significant. This could be associated with the competence of the technicians and HD nurses in preventing, early detecting and remedying the complications which are usually related to HD machine and its various components.
Table 1: Duration of HD.

\begin{tabular}{|l|c|c|c|}
\hline Duration-Minutes & $\begin{array}{c}\text { No. of Clinical } \\
\text { complications (\%) }\end{array}$ & $\begin{array}{c}\text { No. of nonclinical } \\
\text { complications (\%) }\end{array}$ & Total (\%) \\
\hline$\leq 120$ & $2(0)$ & $11(21.2)$ & $11(21.2)$ \\
\hline $121-150$ & $0(0)$ & $2(3.8)$ & $2(3.8)$ \\
\hline $151-180$ & $2(7.7)$ & $8(15.4)$ & $12(23.1)$ \\
\hline $181-210$ & $5(9.6)$ & $19(36.5)$ & $24(46.1)$ \\
\hline $211-240$ & $2(3.8)$ & $1(1.9)$ & $3(5.7)$ \\
\hline Total & $11(21.2)$ & $41(78.8)$ & $52(100)$ \\
\hline
\end{tabular}

Intradialytic blood pressure changes are common and present as intradialytic hypo or hypertension. The relationship between haemodialysis and changes in blood pressure is complex and poorly understood. Intradialytic hypotension has been reported in 15$55 \%$ of HD patients [19] and may be very severe with debilitating cerebrovascular symptoms necessitating premature termination of the $\mathrm{HD}$ as observed in $5.7 \%$ in this study. It is the commonest clinical complication causing PTHD in this study however in other studies it constitute less than $3 \%$ of causes of PTHD $[14,15]$. Stefánsson BV, et al. [20] reported that intradialytic hypotension is associated with poor outcome of cardiovascular diseases and all-cause mortality in HD patients. Thus the need for early detection and intervention which may necessitate discontinuation of the HD as in this study. Predialysis patients assessment including antihypertensive and cardiac review, placing patient in trendelenburg position, modulation of ultrafiltration, intradialytic temperature and blood flow rate, sodium profiling, administration of hypertonic solution, inotropes and vasopressors are measures to prevent/or manage intradialytic hypotension.

Intradialytic hypertension has been reported to result from sodium and volume overload, activation of RAAS and sympathetic system, complications of CKD and its treatment. It has been reported to be less prevalent than hypotension occurring in $5-15 \%$ of haemodialysis sessions, the severity varies, however it is associated with higher cardiovascular morbidity and mortality [21]. The interventions include sodium profiling, increasing ultrafiltration, intradialytic antihypertensive therapy and also discontinuing $\mathrm{HD}$ as in this study where it caused PTHD in $1.9 \%$ of HD sessions. Earlier studies did not report intradialytic hypertension as a cause of premature or early termination or sign off of $\mathrm{HD}[14,15]$.

Body weakness, restlessness, headache and muscle cramp were other intra corporeal complications that caused premature termination of HD in this study. They caused $11.4 \%$ of PTHD with body weakness causing $27.3 \%$ of those with clinical manifestations. This systemic presentation which is consistent with other studies results from many cerebrovascular or metabolic disorders. Dyselectrolytaemia and disequilibrium syndrome has been associated with these clinical syndromes including body weakness, restlessness, headache, seizure, loss of consciousness, muscle cramp and occasionally death [22]. Modulation of HD treatment time, correction of the electrolyte, sodium modelling, administration of hypertonic solution etc are some of the modalities that is beneficial in the prevention and management of these complications [12,22,23].

Most of extracorporeal complications are associated with functionality of the haemodialysis apparatus including the machine and usually present as nonclinical complication. The HD machines have inbuilt monitors that detect abnormalities in the HD by alarming, and this affects the adequacy of the HD. These alarms are to protect 
the patient's safety by tracking various haemodialysis parameters including blood flow, dialysate flow, air bubble, temperature and pressures (arterial, venous, transmembrane).

Femoral vascular access was the commonest vascular access used for haemodialysis by patients in this study. This is contrary to KDOQI recommendation that ranked femoral catheters as the least preferred vascular access for HD [24]. The prevalence of the use of femoral catheter in our patient as a result of non-affordability of the recommended access including internal jugular catheters and arteriovenous fistula by the patients. Absence of medical insurance covering renal care and the prevailing poverty in the country also contribute in perpetuating this state. A good vascular catheter ensures an adequate extra corporeal blood flow of at least $300 \mathrm{~mL} /$ minute. Poor vascular access is a common complication and is a major indication for catheter removal in haemodialysis patients [25]. Poor vascular access is the commonest complication in this study and caused PTHD. It was the commonest extra corporeal cause of PTHD accounting for $29.3 \%$ of those complications. This is very high when compared with reports of another study which reported that vascular access related problems caused early termination of dialysis in less than $3 \%$ of $\mathrm{HD}$ sessions [15]. Catheter dysfunction usually results from mechanical issues including kinking/mal positioning of the catheter, blood clot in the catheter and occasionally narrowing of the catheter lumen by fibrin sheath $[25,26]$.

Extracorporeal blood clotting in patients undergoing haemodialysis though reported as uncommon was reason for discontinuing HD in $5.7 \%$ of patients who had premature termination of HD [14]. Extracorporeal blood clotting reduces HD adequacy, increases blood loss and other complications of HD. Careful patient selection, appropriate anticoagulation and blood flow rate are some of the preventive measures [27].

Dialysate alarm occurs when the chemical content of the dialysate are not well mixed or dialysate concentration is inappropriate for the machine as observed in this study. Dialysate alarm was a very common non clinical complication in this study causing premature stoppage of HD in $20.8 \%$. Also bicarbonate related complication which caused PTHD in $1.9 \%$ of HD sessions in this study is another cause of dialysate related complication. Davenport A [28] reported that dialysate related challenges is a common intradialytic complication, however contrary to this study it is not a common cause of PTHD [14,15]. Some of the dialysate related challenges including clogging of dialysate filter, abnormal dialysate temperature and flow will also trigger dialysate alarm [29].

All haemodialysis machines have air bubble detector that detects and activates the system to trap the air bubble thus preventing it from entering the intra corporeal circulation to cause air embolism. The volume of the air bubble is usually small and it is detected/removed by the inbuilt system in the machine. Occasionally the volume and diameter of the air bubble is very large necessitating terminating the dialysis as occurred in $11.3 \%$ in this study. The source of the air is usually the arterial end of the vascular access where air can be sucked in as a result of sub atmospheric pressure created by the blood pump, crack in the venous tubing and occasionally air diffusing from the dialysate side of the dialyzer across the membrane to the blood [30].

Large quantity of purified water is required to perform dialysis treatment safely. The water from source usually passed through many processes of purification including reverse osmosis and ultra violet light to produce ultrapure water safe for dialysis. A session of conventional HD of 4 hours may require up to 150 liters of this ultrapure water. Thus water movement from source requires a certain pressure to pass through the various purification processes and also to the HD machines. Suboptimal water pressure in any of these steps will impact adversely on the haemodialysis, occasionally aborting the HD session. Suboptimal water pressure caused $9.4 \%$ of PTHD sessions in this study. Inadequate water pressure can occur for several reasons including pressure from the main water source, height of the overhead tank, shared water source, faulty water pump.

Trans Membrane Pressure (TMP) monitors the filtration function and membrane integrity of the dialyser filters. The monitor detects membrane leak/rupture, loss of membrane permeability and obstruction of the capillaries. A challenge in TMP was also noted as a cause of premature termination of dialysis in this study, causing $1.9 \%$ of incomplete sessions. High ultrafiltration volume also has the potential to cause high TMP and can cause cellular damage, cytokine activation and haemodialyser filtration failure. Thus the need to monitor TMP to ensure optimum treatment and safety to the patients [31].

It was also noted that $3.8 \%$ of those with PTHD were due to patient's insistence on termination without detecting any obvious intradialysis complication. This is much lower than the reports of $7.1 \%$ and $37.5 \%$ in Iraq and America respectively [14,15]. The lower prevalence of our patient's noncompliance may be attributed to high level of poverty among the patients and cost of the HD was borne by the patient. Thus they endeavour to complete any HD session they were able to afford except if there is unavoidable complications.

The experience of the haemodialysis staff including the nurses and technicians may have significantly contributed to the prevalence of PTHD. There was no structured training as most of them had "adhoc" training because of the urgent need of the center in the population. So they were still learning on the job and thus some causes of the PTHD including machine related complications could have been averted. Furthermore, the poor economic state of the country and the patients may have played a role including the inability to adhere to KDOQI recommendations especially the use of vascular access and frequency of dialysis. Most of the patients could only afford femoral vein vascular access and less than a session of dialysis per week. This will increase the rate of poor flow, hypertension, ultrafiltration and antecedent hypotension, cramps, restlessness, etc.

The limitations encountered in this study include the inability to follow up patients and asses possible patient's outcome due to the cross section and retrospective nature of the study. A large multicenter prospective study of longer duration will obviate these limitations.

In conclusion, the prevalence of PTHD is $12.8 \%$ and most of the patients had only a single episode of PTHD. Nonclinical complications were the commonest cause of PTHD, causing $78.8 \%$ of PTHD in this study. Challenges with vascular access and dialysate alarm were the commonest nonclinical causes of PTHD and intradialytic hypotension and body weakness were the commonest clinical causes of PTHD. Improvement in training of the haemodialysis operators especially the technicians and nurses with better understanding of operation of the HD machines and HD procedure will reduce the frequency of PTHD, and thus improve the adequacy and outcome of HD.

\section{Acknowledgement}

We, the authors thank the staff of haemodialysis unit, department of medicine ESUT teaching hospital Enugu Parklane. 


\section{References}

1. Grassmann A, Gioberge S, Moeller S, Brown G (2005) ESRD patients in 2004: global overview of patient numbers, treatment modalities and associated trends. Nephrol Dial Transplant 20: 2587-2593.

2. Naicker S (2009) End-stage renal disease in sub-Saharan Africa. Ethn Dis 19: S13-S15.

3. Bambgoye EL (2003) Haemodialysis: management problems in developing countries, with Nigeria as a surrogate. Kidney Int Suppl s93-S95.

4. Okwuonu CG, Chukwuonye II, Adejumo OA, Agaba El, Ojogwu LI (2017) Prevalence of chronic kidney disease and its risk factors among adults in a semi-urban community of South-East Nigeria. Niger Postgrad Med J 24: 81-87.

5. Ibrahim A, Ahmed MM, Kedir S, Bekele D (2016) Clinical profile and outcome of patients with acute kidney injury requiring dialysis-an experience from a haemodialysis unit in a developing country. BMC Nephrol 17: 91.

6. Ulasi II, ljoma CK (2010) The enormity of chronic kidney disease in Nigeria: the situation in a teaching hospital in South-East Nigeria. J Trop Med 2010: 501957.

7. Collins AJ, Foley RN, Chavers B, Gilbertson D, Herzog C, et al. (2014) US Renal Data System 2013 Annual Data Report. Am J Kidney Dis 63: A7.

8. Kidney Disease: Improving Global Outcomes (KDIGO) CKD Work Group (2013) KDIGO 2012 Clinical Practice Guideline for the Evaluation and Management of Chronic Kidney Disease. Kidney Int Suppl 3: 1-150.

9. Xue JL, Eggers PW, Agodoa LY, Foley RN, Collins AJ (2007) Longitudinal study of racial and ethnic differences in developing end-stage renal disease among aged medicare beneficiaries. J Am Soc Nephrol 18: 1299-1306.

10. Norris K, Nissenson AR (2008) Race, gender, and socioeconomic disparities in CKD in the United States. J Am Soc Nephrol 19: 12611270.

11. Goodkin DA, Bragg-Gresham JL, Koenig KG, Wolfe RA, Akiba T, et al. (2003) Association of comorbid conditions and mortality in hemodialysis patients in Europe, Japan, and the United States: The Dialysis Outcomes and Practice Patterns Study (DOPPS). J Am Soc Nephrol 14: 3270-3277.

12. Davenport A (2006) Intradialytic complications during hemodialysis. Hemodial Int 10: 162-167.

13. National Kidney Foundation (2015) KDOQI Clinical Practice Guideline for Hemodialysis Adequacy: 2015 update. Am J Kidney Dis 66: 884930.

14. AL-Jabbar Kadhim MA, Malik AS (2008) Prevalence and causes of early termination of haemodialysis sessions. Iraq J Med Sci 6: 4-13.

15. Rocco MV, Burkat MJ (1993) Prevalence of missed treatment and early sign-offs in haemodialysis patients. J Am Soc Nephrol 4: 11781183.
16. Held PJ, Levin NW, Bovbjerg RR, Pauly MV, Diamond LH (1991) Mortality and duration of hemodialysis treatment. JAMA 265: 871875.

17. Held PJ, Brunner F, Odaka M, Garcia JR, Port FK, et al. (1990) Fiveyear survival for end-stage renal disease patients in the United States, Europe, and Japan, 1982 to 1987. Am J Kidney Dis 15: 451457.

18. Blagg CR (1993) The US Renal Data System and the Case-Mix Severity Study. Am J Kidney Dis 21: 106-108.

19. Brandshaw W (2014) Intradialytic hypotension: A literature review. Renal society Australiasia journal 10: 22-29.

20. Stefánsson BV, Brunelli SM, Cabrera C, Rosenbaum D, Anum E, et al. (2014) Intradialytic hypotension and risk of cardiovascular disease. Clin J Am Soc Nephrol 9: 2124-2132.

21. Van Buren PN, Kim C, Toto RD, Inrig JK (2012) The prevalence of persistent intradialytic hypertension in a hemodialysis population with extended follow-up. Int J Artif Organs 35: 1031-1038.

22. Prabhakar, Singh RG, Singh S, Rathore SS, Choudhary TA (2015) Spectrum of intradialytic complications during hemodialysis and its management: A single-center experience. Saudi J Kidney Dis Transpl 26: 168-172.

23. Mistry K (2019) Dialysis disequilibrium syndrome prevention and management. Int J Nephrol Renovasc Dis 12: 69-77.

24. National Kidney Foundation KDOQI Work Group (2006) Clinical practice guidelines for vascular access. Am J Kidney Dis 48: S176-S247.

25. National Kidney Foundation KDOQI Work Group (2006) Clinical practice guidelines for vascular access. Am J Kidney Dis 48: S248-S273.

26. Niyyar VD, Chan MR (2013) Interventional nephrology: Catheter dysfunction--prevention and troubleshooting. Clin J Am Soc Nephrol 8: $1234-1243$.

27. Boyer CJ, Swartz RD (1991) Severe Clotting During Extracorporeal Dialysis Procedures. Semin Dial 4: 69-71.

28. Davenport A (2015) Complications of hemodialysis treatments due to dialysate contamination and composition errors. Hemodial Int 19: S30-S33.

29. Young BA (2015) Dialysis circuit review. ASN dialysis curriculum, ASN advisory group 16-20.

30. Wagner S, Rode C, Wojke R, Canaud B (2015) Observation of microbubbles during standard dialysis treatments. Clin Kidney J 8: 400-404.

31. Pedrini LA, Cozzi G, Faranna P, Mercieri A, Ruggiero P, et al. (2006) Transmembrane pressure modulation in high-volume mixed hemodiafiltration to optimize efficiency and minimize protein loss, Kidney Int 69: 573-579. 